\title{
Gastric-type well-differentiated adenocarcinoma and pyloric gland adenoma of the stomach
}

\author{
Ryoji Kushima ${ }^{1}$, Michael Vieth ${ }^{2}$, Franz Borchard ${ }^{3}$, Manfred Stolte ${ }^{2}$, Ken-ichi Mukaisho ${ }^{4}$, \\ and TAKANORI HATTORI ${ }^{4}$ \\ ${ }^{1}$ Division of Diagnostic Pathology, Shiga University of Medical Science Hospital, Otsu 520-2192, Japan \\ ${ }^{2}$ Institute of Pathology, Klinikum Bayreuth, Bayreuth, Germany \\ ${ }^{3}$ Institute of Pathology, Klinikum Achaffenburg, Achaffenburg, Germany \\ ${ }^{4}$ Department of Pathology, Shiga University of Medical Science, Otsu, Japan
}

\begin{abstract}
Since 1985, when gastric-type well-differentiated adenocarcinomas were demonstrated in hyperplastic polyps of the stomach, we have studied phenotypic expression in gastrointestinal epithelial lesions. The recent discovery of $M U C$ genes coding core proteins of mucin has improved research on the phenotypic expression of gastrointestinal neoplasms. The disease entity of gastric-type well-differentiated adenocarcinoma has recently been accepted, especially in Japan and Europe. This entity has often become a clinicopathological subject of discussion, because its biological behavior is possibly highly malignant, in spite of the difficulty in making endoscopic and histopathological diagnoses. Even under these circumstances, the term "gastric adenoma" usually means flat adenoma of the intestinal type. Gastric-type adenomas have been regarded as exceptional until recently. Although gastric-type adenomas could theoretically be classified into foveolar type and pyloric-gland type, foveolar-type adenoma is, in practice, difficult to distinguish from gastric-foveolar-type adenocarcinoma. In 2003, we first reported systematic clinicopathological analyses of pyloric gland adenoma, demonstrating its unstable and precancerous nature. In this article, we review and discuss the clinicopathological and molecular pathological aspects of gastric-type well-differentiated adenocarcinomas and pyloric gland adenomas, mainly based on our published and unpublished data.
\end{abstract}

Key words Gastric-type adenocarcinoma - Pyloric gland adenoma $\cdot$ Mucin $\mathrm{CGH}$

\section{Introduction}

Gastric carcinomas have been classified into two main histological types. Laurén [1] studied the morphology and mucin properties of advanced gastric cancers, and

Offprint requests to: $\mathrm{R}$. Kushima

Received: February 16, 2006 / Accepted: April 26, 2006 found that gastric carcinomas could be broadly divided into gland-forming adenocarcinomas and poorly differentiated carcinomas, which included signet-ring cell carcinomas. The former were found to retain intestinal features, and the latter tended to disclose a diffusely infiltrative growth pattern; Laurén referred to these as intestinal-type and diffuse-type, respectively, reporting that $53 \%$ of his samples were intestinal-type, 33\% were diffuse-type, and the remaining 14\% were unclassifiable [1].

In the differentiated adenocarcinomas, intestinal metaplasia was often seen in the stomach, and intestinaltype cancers were thought to arise from the intestinal metaplasia. On the other hand, diffuse-type cancers did not retain intestinal characteristics, and they were considered to arise in the ordinary gastric mucosa, which was not involved in intestinal metaplasia [2,3]. In the middle of the 1980s, Helicobacter pylori was found to cause chronic active gastritis, and it was suggested that $H$. pylori played an important role in gastric carcinogenesis. In this respect, a hypothesis was that $H$. pylori caused chronic active gastritis with intestinal metaplasia, resulting in the development of intestinal-type adenocarcinomas [4,5].

However, several studies appeared which described well-differentiated adenocarcinomas arising in nonintestinalized gastric mucosa, and there has been a question whether well-differentiated adenocarcinomas of the stomach were exclusively intestinal type. The recent discovery of $M U C$ genes coding core proteins of mucin has identified the phenotypic expression of gastrointestinal neoplasms [6-8]. The disease entity of "gastric-type well-differentiated adenocarcinoma" has recently been accepted, especially in Japan and Europe. This entity has often been a clinicopathological subject of discussion, especially in Japanese journals, because its biological behavior is possibly highly malignant, in spite of the difficulty of making endoscopic and histopathological diagnoses $[9,10]$. 


\section{Gastric-type well-differentiated adenocarcinoma}

\section{Histopathological and histochemical diagnosis}

Gastric-type adenocarcinoma consists of cuboidal to tall columnar cells with clear mucinous cytoplasm, showing papillary/villous projections in the upper portion and irregular branching/fusion in the middle to deeper portion. The structure in the latter has been called a "shaking-hands structure", which is called "lateral intertubular expansion" in Germany [11], indicating, in our opinion, stromal invasion in the proper mucosa. In addition to these structural characteristics, most important is the nuclear atypia; as well as the lack of surface differentiation, compared to features of nonneoplastic neighboring pits (Fig. 1). Gastric-type cells, especially of the mucous-neck/pyloric-gland type, occasionally have eosinophilic and fine granular cytoplasm, which should not be misinterpreted as showing intestinal-type cells.

Immunohistochemical studies, especially of mucin expression, are useful for additional diagnosis. Mucins are heavily glycosylated glycoproteins that are the major components of the viscous gel covering the surface of the gastrointestinal epithelium. Recent progress in mucin biochemistry has enabled a more detailed distinction between different kinds of mucins. More than ten distinct epithelial mucin genes have recently been identified [12-14], and several antibodies against the core proteins coded by $M U C$ genes have become commercially available. We have used several markers as follows: (1) mucin of the surface gastric epithelium (foveolar cells) - human gastric mucin (HGM) and MUC5AC; (2) mucin of the mucous-neck, pyloricgland, and Brunner's gland cells - HIK1083 and MUC6; and (3) mucin of intestinal goblet cells MUC2. Also, CD10 can be used to demonstrate the brush border of small-intestinal absorptive cells [15]. With these stainings, gastric carcinoma tissues can be divided into four phenotypes: (1) exclusively gastric phenotype, (2) mixed gastric and intestinal phenotype, (3) exclusively intestinal phenotype, and (4) an unclassifiable type without the expression of these markers $[7,8,16]$. The mixed phenotype is further subdivided into gastric-predominant type and intestinalpredominant type. In addition, pepsinogen-1 staining is used to distinguish mucous neck/pseudopylorictype from true pyloric-type cells. Gastric-type welldifferentiated adenocarcinomas, the subject of this article, immunohistochemically correspond mostly to the exclusively gastric phenotype and partly to the predominantly gastric phenotype.

\section{Historical studies}

Kato et al. [17] found that the incidence of welldifferentiated (intestinal-type) adenocarcinomas was higher than that of undifferentiated-type (diffuse-type) carcinomas in the cardiac mucosa, and the cardiac mucosa had a lower degree of intestinal metaplasia, compared to the antral mucosa. This implied that, in the genesis of cardiac adenocarcinomas, intestinal metaplasia does not play a role, suggesting that adenocarcinomas are not always of intestinal type.

Hattori [18] studied the phenotypic characteristics of adenocarcinomas arising in 67 hyperplastic polyps. The hyperplastic polyp consists of hyperplastic foveolar structures and proliferated mucous glands. This kind of polyp is organotypic in the stomach. In the hyperplastic polyp, the incidence of intestinal metaplasia is low. It occurs sporadically, and the type of metaplasia is mostly incomplete. In Hattori's study, three adenocarcinomas were found, and they consisted of cells closely resembling normal foveolar cells. These lesions were thus referred to as gastric-type (foveolar-type) adenocarcinomas. After that, Ishiguro [19] reported a close relationship of gastric-foveolar type adenocarcinomas to diffuse-type carcinomas. In Germany, Borchard and Hengels [20] doubted whether all gland-forming adenocarcinomas showed intestinal differentiation.

Since 1990, when Tatematsu et al. [21] investigated mucin-histochemical phenotypic expression in gastric cancer cells, the disease entity of "gastric-type welldifferentiated adenocarcinoma" has been drawing attention in the field of gastrointestinal pathology. In their study, among 35 gastric-type adenocarcinomas, the surrounding mucosa in 7 cases showed intestinal metaplasia, while the surrounding mucosa in 10 of 40 intestinal-type carcinomas was found to be proper mucosa without intestinal metaplasia. Therefore, they concluded that there was no relationship between the phenotypic expression of gastric cancer and intestinal metaplasia of the mucosa giving rise to the cancer. However, in investigations of the histogenesis of cancer it is necessary to include the smaller carcinomas. In 1993, Kushima and Hattori [22] examined the phenotypic expressions of early gastric adenocarcinomas, which were not associated with hyperplastic polyps. They randomly selected 65 intramucosal adenocarcinomas; 43 were differentiated adenocarcinomas and 22 were the poorly differentiated type, the so-called diffuse-type. The result was surprising in that 10 of the 43 differentiated adenocarcinomas $(23.2 \%)$ were gastric type, 13 were intestinal-type, and the remaining 20 were mixed type. Watanabe et al. [23] reported that 16 of $135(12 \%)$ microcarcinomas of the differentiated type were of the gastric foveolar type. They observed that minute gastric-type adenocarcinomas were found in the upper 


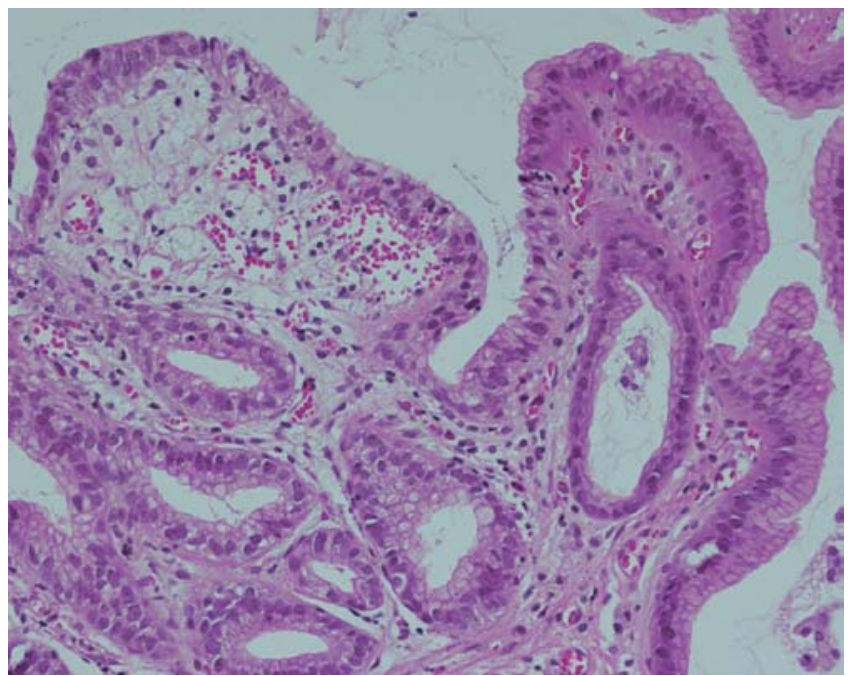

Fig. 1. Biopsy specimen of gastric-type adenocarcinoma. In adenocarcinomatous tubules showing nuclear atypia, there is a lack of surface differentiation
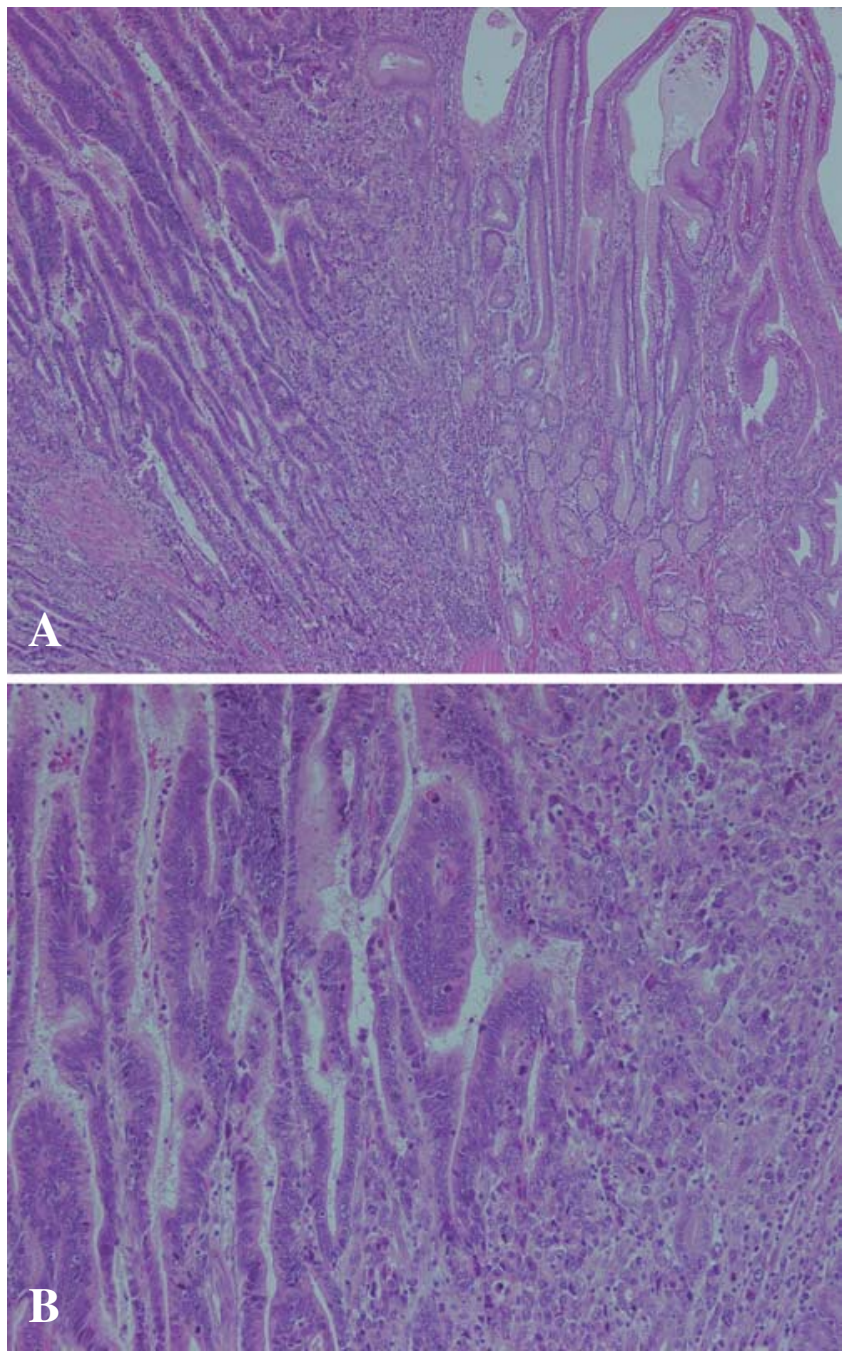

half layer of the gastric proper mucosa, accompanied by pyloric glands in the lower half layer. Gastric-type adenocarcinomas, therefore, may arise in the generative zone of the gastric proper mucosa and grow towards the upper level of the mucosa, often showing a papillary structure.

\section{Variations of gastric-type well-differentiated adenocarcinomas}

Figure 2 shows a case of gastric-type adenocarcinoma harboring some characteristic findings. The tumor is
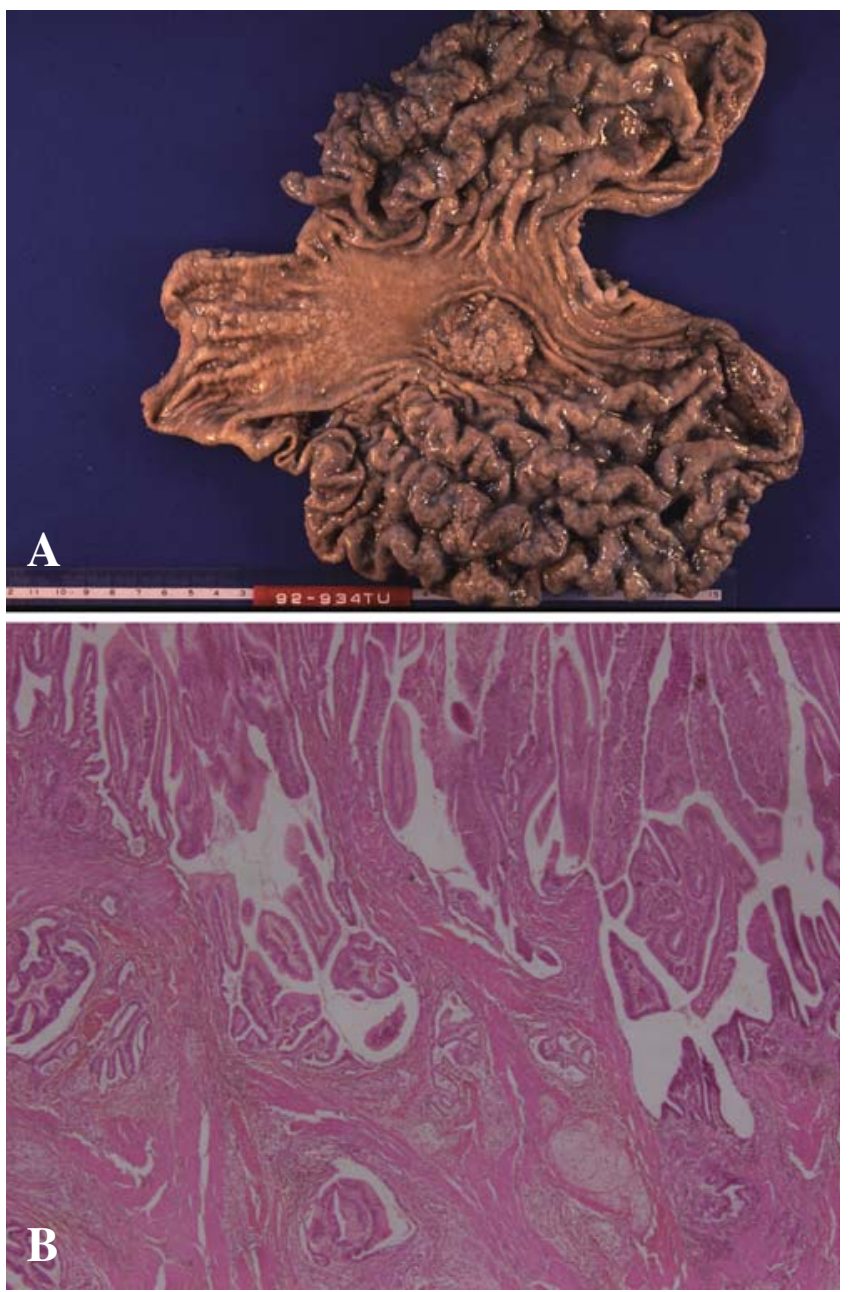

Fig. 3A,B. Very/extremely well-differentiated adenocarcinoma. A An elevated (0-I) tumor in the upper angle. B Papillary adenocarcinoma similar to foveolar hyperplasia invading the proper muscular layer

Fig. 2A,B. Characteristic findings of gastric-type adenocarcinoma. A Adenocarcinoma is surrounded by foveolar hyperplasia. B In the deeper mucosa, transition to poorly differentiated adenocarcinoma is seen 
surrounded by marked foveolar hyperplasia, appearing to arise from a hyperplastic polyp of foveolar type, and transition from very well-differentiated adenocarcinoma to diffuse-type carcinoma is seen in the deeper mucosa.

\section{Prediffuse type}

Although most minute gastric carcinomas (smaller than $5 \mathrm{~mm}$ ) are found to be differentiated-type adenocarcinomas, the ratio of differentiated type to diffuse type becomes about 1 to 1 in the advanced stage. This implies that some differentiated-type adenocarcinomas possibly change into diffuse-type carcinomas. Welldifferentiated adenocarcinomas of gastric type, extending more than $1 \mathrm{~cm}$ in the proper mucosa, tend to harbor diffuse-type elements [19]. If they invade into the submucosal layer or deeper, they progress to poorly differentiated adenocarcinomas of nonsolid type. On endoscopic examination, gastric-type adenocarcinomas of the prediffuse type often show a shallow depression $(0-$ IIc) or a shallow depression with lower elevation (0IIc + IIa); the color is normal and it is difficult to detect the border of the tumor [9]. It is difficult to predict the possibility of progression from the differentiated type to diffuse type in small biopsy specimens. However, prominent "shaking-hands structures" appear to be a sign of change into the diffuse type. Even if the tumor does not invade into the submucosal layer, adenocarcinomas with prominent shaking-hands structures tend to extend superficially in the mucosa. In such a case, pathologists should give this information to endoscopists and surgeons.

\section{Very/extremely well-differentiated adenocarcinoma $(V W D A)$}

We occasionally encounter very well-differentiated and very low-grade adenocarcinoma that is deeply invading and without diffuse-type elements (Fig. 3). Some authors have called this type of cancer extremely welldifferentiated adenocarcinoma (EWDA) [24]. In this category, there are small-intestinal-type and gastrictype adenocarcinomas, which may be misinterpreted as intestinal metaplasia and foveolar hyperplasia, respectively, by general pathologists. Although VWDAs tend to show elevated growth as compared to prediffuse-type carcinomas, there is no characteristic appearance. We have experienced some depressed VWDAs. If the tumor displays a submucosal-tumor-like appearance, pathologists should take the possible presence of submucosal gastric glands or heterotopic pancreas into consideration.

\section{Remnant gastric cancer}

In remnant gastric cancers, there have been reported to be a higher incidence of gastric-type well-differentiated adenocarcinoma [25]. Several classifications of remnant gastric cancer have been proposed; according to the original lesion (malignant or not), the anastomostic method (Billroth-I or II), and the interval between the first and second operations. Gastric-type welldifferentiated adenocarcinomas are most frequently found in the group with a longer time after surgery, performed by the Billroth-II method, for benign disease, in particular for duodenal ulcer [26,27]. The corpus mucosa is not atrophic in patients with duodenal ulcer, and remnant cancers often arise in the mucosa of stomal polypoid hyperplastic gastritis. Stomal polypoid hyperplastic gastritis is characterized by tortuously structured foveolar hyperplasia and cystically dilated (pseudo)pyloric glands, which become prominent according to the interval time since the operation [28]. In stomal polypoid hyperplastic gastritis, intestinal metaplasia is rarely seen.

\section{Adenocarcinoma arising in the gastric cardia}

As already mentioned, Kato et al. [17] found a poor relationship between differentiated adenocarcinomas and intestinal metaplasia in the gastric cardia. Recent progress in mucin immunohistochemistry has disclosed a higher incidence of gastric phenotype in early adenocarcinomas of the gastric cardia than in those of the distal stomach [29].

\section{Adenocarcinoma arising from hyperplastic polyps}

Eight years after Hattori's [18] discovery, Kushima and Hattori [22] collected a large number of hyperplastic polyps, obtained by endoscopic resection, to estimate the frequency and determine the detailed characteristics of gastric-type adenocarcinomas, using advances in mucin histochemistry. Eleven (78.6\%) of 14 differentiated-type carcinomas in hyperplastic polyps were gastric-type adenocarcinomas and the others showed a mixed type, with gastric and intestinal features.

\section{Chromosomal abnormalities in gastric-type well-differentiated adenocarcinomas}

We examined chromosomal abnormalities in 13 cases of early well-differentiated gastric adenocarcinomas of the completely gastric phenotype, by means of laser capture microdissection and comparative genome hybridization (CGH). Most cases showed low-grade nuclear atypia. Gains of 1p36-pter, 9q34-qter, 17p12-pter, 17q24-qter, $20 \mathrm{pq}$, and 22q; losses of $6 \mathrm{q}$ and 189 ; and amplification of $15 \mathrm{q} 26$ were frequently detected. Adenocarcinomas arising in a hyperplastic polyp and a pyloric gland adenoma displayed the same tendency. In spite of showing lowgrade histopathological atypia, gastric-type adenocarcinomas, even in the early stage, were shown to harbor considerable chromosomal abnormalities, as has been 
previously reported in advanced gastric carcinomas and cancer cell lines [10].

\section{Gastric-type adenoma (pyloric gland adenoma)}

While the disease entity of gastric-type welldifferentiated adenocarcinoma has recently been accepted, the term "gastric adenoma" usually means a flat adenoma of the intestinal type. Adenomas of gastric type have been regarded as exceptional until recently.

\section{Phenotypes of gastric adenomas}

\section{Intestinal-type adenomas dysplasia}

Most adenomas are intestinal-type, as revealed by mucin histochemistry. We recently compared the expression of $M U C$ genes in adenomas and differentiated-type adenocarcinomas [7]. Most adenomas were strongly positive for the intestinal markers, MUC2 and CD10, but were negative for the gastric markers, MUC5AC and MUC6. On the contrary, about $30 \%$ of adenocarcinomas were intestinal type, and these were positive for the intestinal mucin markers MUC2 and CD10, but negative for gastric markers. Seventy percent of the adenocarcinomas retained gastric phenotypes (they were gastric type or mixed type), and they generally disclosed positivity for the gastric markers MUC5AC and MUC6. These findings indicate that the adenomacarcinoma sequence is not a common event in stomach carcinogenesis, because it is difficult to explain how cells with gastric phenotypes arise from cells with exclusively intestinal phenotypes.

\section{Gastric-type adenoma (pyloric gland adenoma)}

Although gastric-type adenomas could theoretically be classified into foveolar type and pyloric-gland type, foveolar-type adenoma is, in practice, difficult to distinguish from gastric-foveolar-type adenocarcinoma. In fact, most foveolar-type adenomas presented by Abraham et al. [30,31] have been diagnosed as intramucosal adenocarcinomas by German and Japanese specialists.

Pyloric gland adenoma was first characterized by Borchard et al. [32], and Watanabe et al. [33] described a similar lesion in the World Health Organization (WHO) classification of gastric tumors in 1990. Borchard presented two cases of pyloric gland adenoma with transition to adenocarcinoma at slide seminars in Germany in 1986 and 1987 (unpublished data). Similar adenomas of the gastric type were subsequently described in gastric heterotopia in the duodenum [34], in the pancreatic duct [35], and, in particular, in the gallbladder [36,37]. In 2003, we first reported systematic clinicopathological analyses of pyloric gland adenoma,

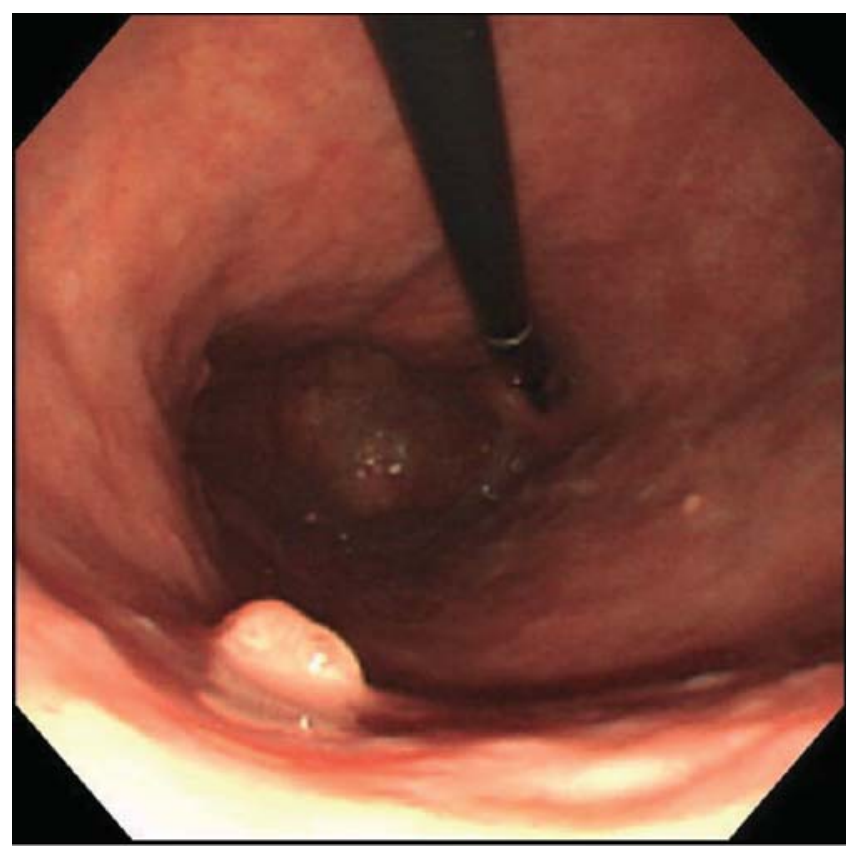

Fig. 4. Endoscopic finding of pyloric gland adenoma. There is a nodular/dome-like polyp in the upper corpus

in English language and Japanese journals [38,39]. Since then, there have been reported cases of pyloric gland adenoma arising in the proper esophagus [40], Barrett's esophagus [41], and in gastric heterotopia of rectum [42].

\section{Clinicopathological findings of pyloric gland adenoma}

Pyloric gland adenomas occur predominantly in old age (73 \pm 12.8 years) and more frequently in women $(75 \%)$ than in men; they tend to arise in the corpus mucosa of the stomach, showing close association with (pseudo)pyloric-gland metaplasia of fundic glands $[38,39]$. Cases reported in Europe are often associated with autoimmune gastritis. Endoscopic study usually shows a nodular and dome-like lesion (Fig. 4). If the tumor appears to be a submucosal tumor endoscopically, it may be arising from submucosal gastric glands. The tumor consists of narrow or cystically dilated tubules, which are not fused or are irregularly branched. The tubules are lined by cuboidal to prismatic columnar epithelial cells that contain clear cytoplasm or pale eosinophilic cytoplasm. Superficial tumor cells are slightly larger in size than deeper ones. The tumor cell nuclei are small and oval or round in shape, and contain small but conspicuous nucleoli. Immunohistochemically, most tumor glands are strongly positive for MUC6, except in the superficial layer. MUC5AC tends to be positive in the superficial layer, but it is also expressed in the deeper portion. MUC2 and CD10 are generally nega- 

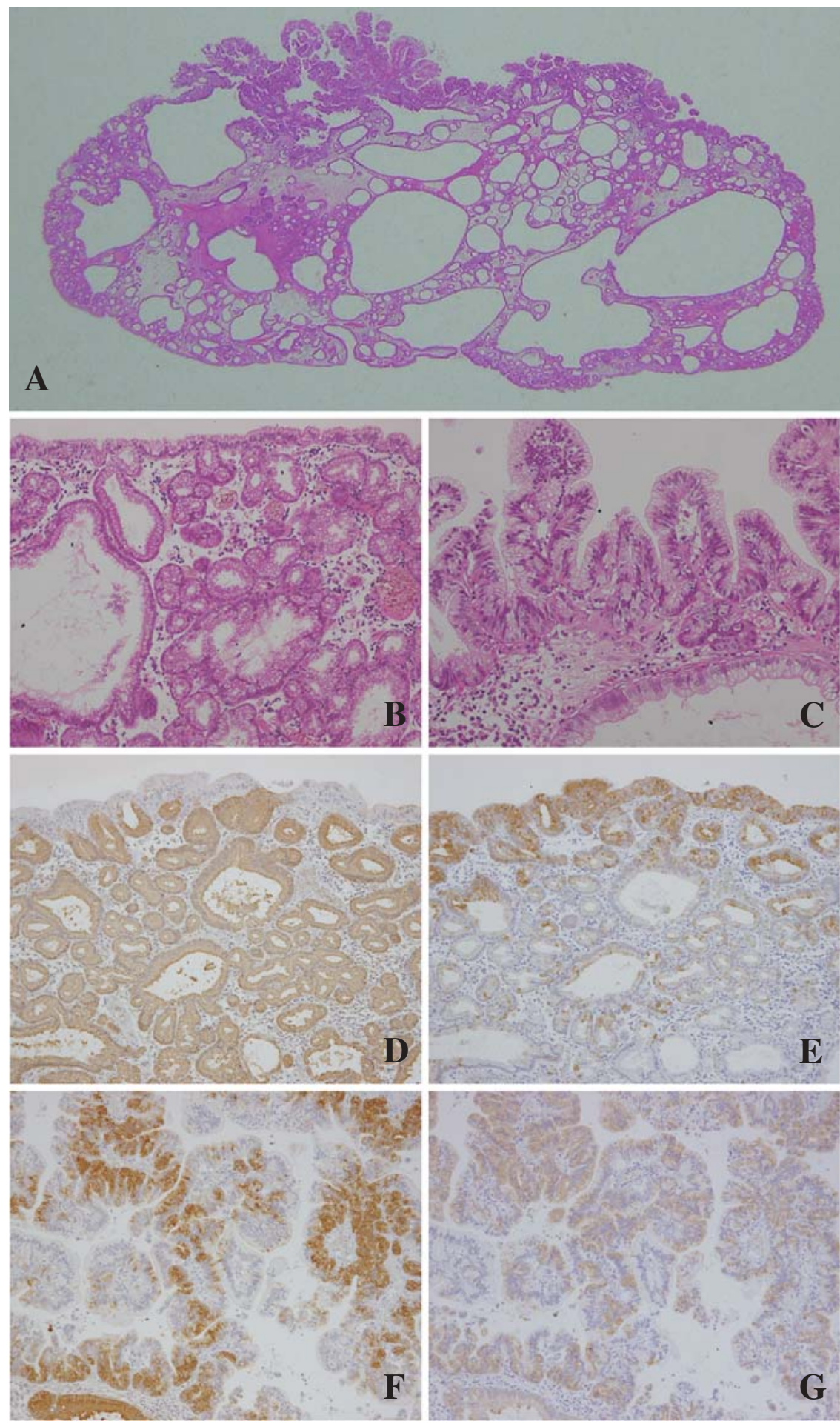

Fig. 5A-G. Pyloric gland adenoma with transition to adenocarcinoma. A Irregular papillary/villous structure is seen in the upper polyp. B Typical histological finding of pyloric gland adenoma. C Adenocarcinomatous area, showing focal destruction of basement membrane. D MUC6positivity in adenoma. E MUC5ACpositivity in adenoma. F MUC6-positivity in adenocarcinoma. G MUC5ACpositivity in adenocarcinoma tive in these tumors. The positivity of tumor cells for both MUC5AC and MUC6 means that they have an immature and unstable nature. MIB-1-positive proliferating cells are usually localized in the upper layer of the tumor, but are also scattered throughout the tumor. Histopathological findings of pyloric gland adenoma are shown in Fig. 5.
Chromosomal abnormalities in pyloric gland adenomas

In four of five pyloric gland adenomas studied, micodissection and CGH analyses revealed some chromosomal abnormalities common to invasive gastric adenocarcinoma, such as gains of $17 \mathrm{pq}$ and 20q; and losses 

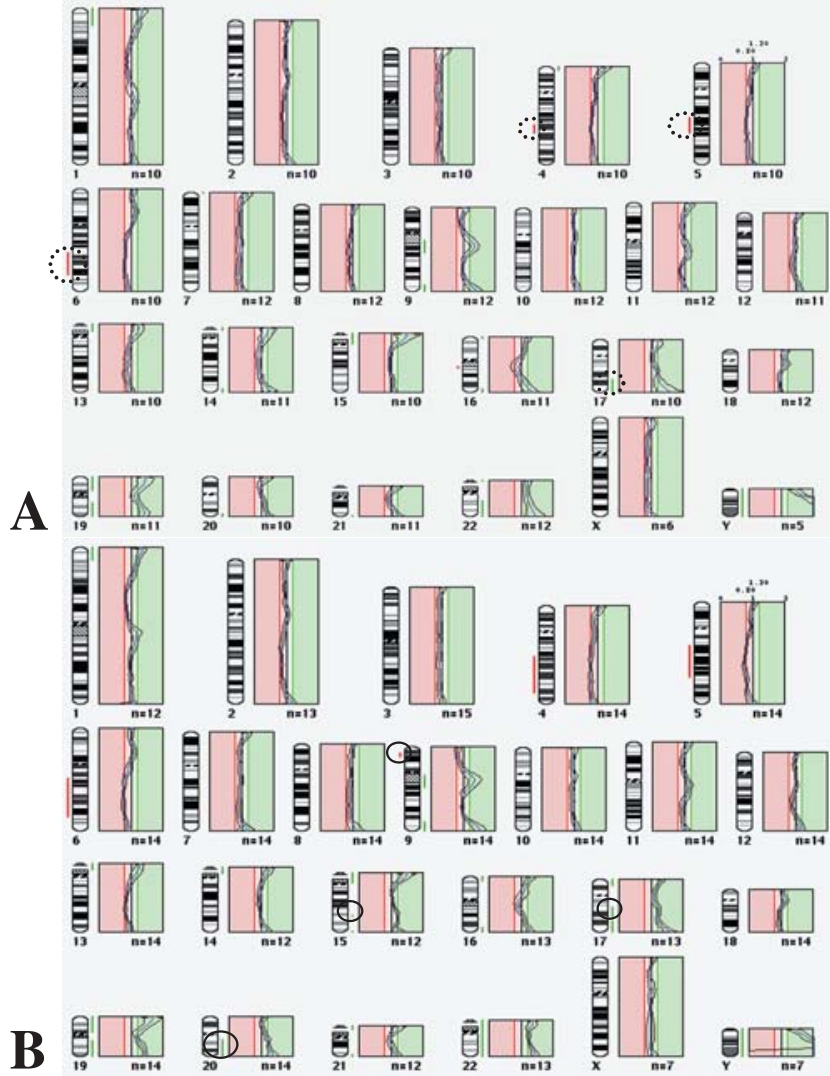

Fig. 6A,B. Comparative genome hybridization $(\mathrm{CGH})$ profile in adenoma and adenocarcinoma. A Adenoma. B Adenocarcinomatous area. Area shown by dotted line shows common chromosomal changes in the two lesions. Area shown by continuous line shows additional chromosomal changes in the developing adenocarcinoma

of $4 \mathrm{q}, 5 \mathrm{q}$, and $6 \mathrm{q}$ [39]. In a case of pyloric gland adenoma that we first found to arise in Barrett's epithelium of the esophagus, there were losses on 2p24-25.2, 2q14.1-ter, 5q31.3-32, 6q23-24, 8q23-24.2, 11q22.3-24, and 18q21.1-22 [41]. In our experience, pyloric gland adenomas have been regarded as hyperplasias or hamartomas and this entity has not been accepted, especially in the Anglo-American literature, in the past. However, our studies suggest the unstable and precancerous nature of pyloric gland adenomas. In $20 \%-30 \%$ of pyloric gland adenomas, transition to severe dysplasia and/or differentiated adenocarcinomas of predominantly gastric phenotype has been noted [38,39]. Endoscopists and pathologists should be on the lookout for this type of tumor in the gastrointestinal tract during routine examinations.

\section{Pyloric gland adenoma-adenocarcinoma sequence}

Very recently, we encountered a very interesting case of pyloric gland adenoma with transition to intramucosal

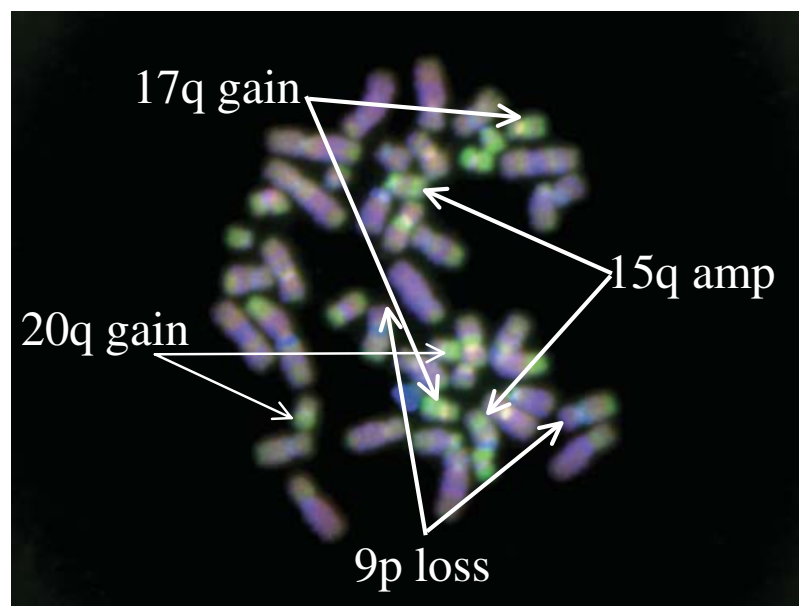

Fig. 7. $\mathrm{CGH}$ analysis in adenocarcinomatous area. Tumor DNA and sex-matched reference DNA were labeled with Cy 3-dCTP and Cy 5-dCTP, respectively, by random priming. Additional chromosomal changes (17q21-q23, 20q, loss of 9p21-p23, and amplification of 15q26) were detected in the adenocarcinomatous component (arrow)

invasive adenocarcinoma (Fig. 5). A 75-year-old man had a small nodular and polypoid lesion in the gastric cardia, and the tumor was endoscopically resected. Immunohistochemically, the layered structure of MUC5AC/MUC6 found in the adenoma was deranged in the adenocarcinomatous area. MUC2 and CD10 were negative in the tumor. By CGH analyses, in the adenomatous component (Fig. 5B), losses of 4q, 5q, and 6q; and gain of 17q, were detected (Fig. 6A). Moreover, in the adenocarcinomatous component (Fig. 5C), gains of $20 \mathrm{q}$ and $17 \mathrm{q} 21-\mathrm{q} 23$; amplification of $15 \mathrm{q} 26$, and loss of 9p21-p23 were added to all the chromosomal changes already detected in the surrounding pyloric gland adenoma (Fig. 6B, 7). This study is the first successful demonstration of a "pyloric gland adenomaadenocarcinoma sequence" by analyses of mucin immunohistochemistry and CGH.

\section{References}

1. Laurén P. The two main histological types of gastric carcinoma: diffuse and so-called intestinal-type carcinoma. Acta Pathol Microbiol Scand 1965;82:308-14.

2. Nakamura K, Sugano H, Takagi K. Carcinomas of the stomach: its histogenesis and histological appearances. Gann 1968;59:2518 .

3. Sugano H, Nakamura K, Kato Y. Pathological studies on human gastric cancer. Acta Pathol Jpn 1982;32:329-47.

4. Parsonnet J, Vandersteen D, Goates J, Sibley RK, Pritikin J, Chang Y. Helicobacter pylori infection in intestinal-, and diffusetype gastric adenocarcinomas. J Natl Cancer Inst 1991;83:640-3.

5. Correa P. Helicobacter pylori and gastric carcinogenesis. Am J Surg Pathol 1995;19 (Suppl 1):S37-43.

6. Reis CA, David L, Correa P, Carneiro F, de Bolos C, Garcia E, et al. Intestinal metaplasia of human stomach displays distinct 
patterns of mucin (MUC1, MUC2, MUC5AC, and MUC6) expression. Cancer Res 1999;59:1003-7.

7. Tsukashita S, Kushima R, Bamba M, Sugihara H, Hattori T. MUC gene expression and histogenesis of adenocarcinoma of the stomach. Int J Cancer 2001;94:166-70.

8. Shiroshita H, Watanabe H, Ajioka Y, Watanabe G, Nishikura K, Kitano S. Re-evaluation of mucin phenotypes of gastric minute well-differentiated-type adenocarcinomas using a series of HGM, MUC5AC, MUC6, M-GGMC, MUC2 and CD10 stains. Pathol Int 2004:54:311-21.

9. Oda I, Gotoda T, Hasuike N, Hamanaka H, Eguchi T, Minami S, et al. Endoscopic features of differentiated-type early gastric carcinoma with gastric mucin phenotype (in Japanese). Stomach Intestine 2003;38:684-92.

10. Kushima R, Mukaisho K, Tsukashita S, Vieth M, Stolte M, Hattori $\mathrm{T}$, et al. Molecular biological characteristics of early stomach adenocarcinoma of the completely gastric phenotype revealed by laser capture microdissectin and comparative genomic hybridization (in Japanese). Stomach Intestine 2003;38: 707-21.

11. Borchard F. Formen und Nomenklatur der gastrointestinalen Epithelexpansion: Was ist Invasion? Verh Dtsch Ges Pathol 2000;84:50-61.

12. Lesuffleur T, Zweibaum A, Real FX. Mucins in normal and neoplastic human gastrointestinal tissues. Crit Rev Oncol Hematol 1994;17:153-80.

13. Williams SJ, Wreschner DH, Tran M, Eyre HJ, Sutherland GR, McGuckin MA. Muc13, a novel human cell surface mucin expressed by epithelial and hemopoietic cells. J Biol Chem 2001; 25:18327-36.

14. Yin BW, Dnistrian A, Lloyd KO. Ovarian cancer antigen CA125 is encoded by the MUC16 mucin gene. Int J Cancer 2002;98:73740.

15. McIntosh GG, Lodge AJ, Watson P, Hall AG, Wood K, Anderson JJ, et al. NCL-CD10-270: a new monoclonal antibody recognizing CD10 in paraffin-embedded tissue. Am J Pathol 1999;154:77-82.

16. Kabashima A, Yao T, Sugimachi K, Tsuneyoshi M. Relationship between biologic behavior and phenotypic expression in intramucosal gastric carcinomas. Hum Pathol 2002;33:80-6.

17. Kato Y, Sugano H, Wada J, Nakamura K. Histogenesis of the cardiac carcinoma (adenocarcinoma) in comparison with that of the antral carcinoma (in Japanese). Stomach Intestine 1978;13: 1509-15.

18. Hattori T. Morphological range of hyperplastic polyps and carcinomas arising in hyperplastic polyps of the stomach. J Clin Pathol 1985;38:622-30.

19. Ishiguro S. Histological significance of foveolar type tubular adenocarcinoma of the stomach. Its histogenesis and relationship to undifferentiated carcinoma (in Japanese). Osaka Med J 1987;39: 507-15.

20. Borchard F, Hengels KL. Sind alle drüsenbildenden Magenkazinome intestinale differenziert? Kritische Bemerkungen zur Lurenschen Klassifikation. Verh Dtsch Ges Pathol 1988;72:614.

21. Tatematsu M, Ichinose M, Miki K, Hasegawa R, Kato T, Ito N. Gastric and intestinal phenotypic expression of human stomach cancers as revealed by pepsinogen immunohistochemistry and mucin histochemistry. Acta Pathol Jpn 1990;40:494-504.

22. Kushima R, Hattori T. Histogenesis and characteristics of gastrictype adenocarcinomas in the stomach. J Cancer Res Clin Oncol. 1993;120:103-11.

23. Watanabe H, Kato N, Fuchigami T, Sato T, Iwafuchi M, Ajioka Y, et al. Natural history of gastric carcinoma from analysis of microcarcinoma (in Japanese). Stomach Intestine 1992;27:59-67.

24. Nokubi M, Kawanowa K, Kawata H, Hanatsuka K, Hosoya Y. Extremely well-differentiated adenocarcinoma of the gastric cardia: a unique case with columnar cells and laminated stones. Pathol Int 2004;54:854-60.

25. Yokoyama K, Hattori T. Characteristics and development of stump cancers of the stomach (in Japanese). Nippon Shokakibyo Gakkai Zasshi 1997:94:261-7.

26. Yao T, Yoshimura D, Tsuneyosi M, Nakamura N, Hirahashi M, Matsui N, et al. Clinicopathological features and histogenesis of remnant gastric cancer (in Japanese). Stomach Intestine 2004;39: 997-1008.

27. Matsui N, Yao T, Akazawa K, Nawata H, Tsuneyoshi M. Different characteristics of carcinoma in the gastric remnant: histochemical and immunohistochemical studies. Oncol Rep 2001;8:17-26.

28. Borchard F. Chemisch-reaktive Gastritis. Pathologe 2001;22:4455.

29. Tajima Y, Nakanishi Y, Yoshino T, Kokawa A, Kusano M, Shimoda T. Clinicopathological study of early adenocarcinoma of the gastric cardia: comparison with early adenocarcinoma of the distal stomach and esophagus. Oncology 2001;61:1-9.

30. Abraham SC, Montgomery EA, Singh VK, Yardley JH, Wu TT. Gastric adenomas: intestinal-type and gastric-type adenomas differ in the risk of adenocarcinoma and presence of background mucosal pathology. Am J Surg Pathol 2002;26:1276-85.

31. Abraham SC, Park SJ, Lee JH, Mugartegui L, Wu TT. Genetic alterations in gastric adenomas of intestinal and foveolar phenotypes. Mod Pathol 2003;16:786-95.

32. Borchard F, Ghanei A, Koldovsky U, Henges KJ, Bückmann FW. Gastrale Differenzierung in Adenomen der Magenschleimhaut. Immunohistochemische und elektronenmikroskopische Untersuchungen. Verh Dtsch Ges Pathol 1990;74:528.

33. Watanabe H, Jass JR, Sobin LH. Histological typing of oesophageal and gastric tumours. Berlin Heidelberg New York Tokyo: Springer; 1990.

34. Kushima R, Rüthlein HJ, Stolte M, Bamba M, Hattori T, Borchard F. "Pyloric gland-type adenoma" arising in heterotopic gastric mucosa of the duodenum, with dysplastic progression of the gastric type. Virchows Arch 1999;435:452-7.

35. Kato N, Akiyama S, Motoyama T. Pyloric gland-type tubular adenoma superimposed on intraductal papillary mucinous tumor of the pancreas. Pyloric gland adenoma of the pancreas. Virchows Arch 2002;440:205-8.

36. Takei K, Watanabe H, Itoi T, Saito T. p53 and Ki-67 immunoreactivity and nuclear morphometry of "carcinoma-in-adenoma" and adenoma of the gall-bladder. Pathol Int 1996;46:908-17.

37. Kushima R, Remmele W, Stolte M, Borchard F. Pyloric gland type adenoma of the gallbladder with squamoid spindle cell metaplasia. Pathol Res Pract 1996;192:963-9.

38. Vieth M, Kushima R, Borchard F, Stolte M. Pyloric gland adenoma: a clinico-pathological analysis of 90 cases. Virchows Arch 2003;442:317-21.

39. Kushima R, Mukaisho K, Vieth M, Borchard F, Stolte M, Hattori T. Pyloric-gland-type adenomas of the stomach (in Japanese). Stomach Intestine 2003;38:1377-87.

40. Michal M, Curik R, Matler K, Benes Z. Regarding the paper by Vieth et al. Virchows Arch 442/4:317-321. Virchows Arch 2003; 443:589-90.

41. Kushima R, Vieth M, Mukaisho K, Hattori T, Borchard F, Stolte $\mathrm{M}$, et al. Pyloric gland adenoma arising in Barrett's esophagus with mucin immunohistochemical and molecular cytogenetic evaluation. Virchows Arch 2005;446:537-41.

42. Vieth M, Kushima R, de Jonge JP, Borchard F, Oellig F, Stolte M. Adenoma with gastric differentiation (so-called pyloric gland adenoma) in a heterotopic gastric corpus mucosa in the rectum. Virchows Arch 2005;446:542-5. 